\title{
ANALISIS JALUR DAN APLIKASI SPSS VERSI 25
}

\section{EDISI PERTAMA}

Dr. Marwan Hamid, M.Pd

Program Studi Pendidikan Ekonomi

Fakultas Keguruan dan Ilmu Pendidikan,

Universitas Almuslim

Matang Glumpang Dua, Peusangan, Bireuen,

24267

Email:marwan.dayah@gmail.com

Dr. Ibrahim Sufi, M.Pd

Program Studi Pendidikan Biologi

Fakultas Keguruan dan Ilmu Pendidikan,

Universitas Serambi Mekkah

Batoh, Lueng Bata, Kota Banda Aceh, 23245

Email: himsufi@gmail.com

Drs. Wen Konadi, M.Si

Program Studi Ekonomi Pembangunan

Fakultas Ekonomi, Universitas Almuslim

Matang Glumpang Dua, Peusangan, Bireuen,

24267

Email:win.manan@yahoo.co.id

Drh. Yusrizal Akmal, M.Si

Program Studi Budidaya Perairan, Fakultas

Pertanian,

Universitas Almuslim

Matang Glumpang Dua, Peusangan,

Bireuen, 24267

Email: drh.yusrizal.akmal.msi@gmail.com

Editor

Prof. Dr. Jamaluddin Iddris, M.Ed

Manajemen dan Evaluasi Pendidikan

Universitas Islam Negeri Ar-raniry Banda Aceh

Kopelma Darussalam, Kota Banda, 23111

Email: jamaluddinidris@yahoo.com

Diterbitkan Oleh:

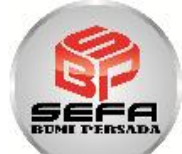

2019 


\section{ANALISIS JALUR DAN APLIKASI \\ SPSS VERSI 2,5 \\ Hak Cipta (C) 2019 pada Penulis}

\section{Oleh}

Dr. Marwan Hamid, M.Pd

Dr. Ibrahim Sufi, M.Pd

Drs. Wen Konadi, M.Si

Drh. Yusrizal Akmal, M.Si

Editor

Prof. Dr. Jamaluddin Iddris, M.Ed

Cover Design

Reza Rizki ${ }^{(S E F A)}$

$$
\underset{\text { T.M.siddiq }}{\text { SayFA }^{(S E)}}
$$

Pracetak dan Produksi

CV. Sefa Bumi Persada

Hak Cipta dilindungi undang-undang.

Dilarang memperbanyak atau memindahkan sebagian atau

seluruh isi buku ini dalam bentuk apapun, baik secara

elektronis maupun mekanis, termasuk memfotokopi, merekam

atau dengan sistem penyimpanan lainnya, tanpa izin tertulis dari Penulis

Penerbit:

\section{SEFA BUMI PERSADA}

Anggota IKAPI : No.021/DIA/2018

J1. B. Aceh - Medan, Alue Awe - Lhokseumawe email: sefabumipersada@gmail.com

Telp. 085260363550

Cetakan I : 2019

ISBN - 978-602-0768-56-4

1. Hal. $137: 21,8 \times 23 \mathrm{~cm}$

I. Judul 


\section{KATA PENGANTAR}

Puji dan syukur penulis panjatkan kehadirat Allah S.W.T. Tuhan Yang Maha Esa berkat rahmat dan karuniaNya, penulis dapat menyelesaikan buku ajar berjudul "Analisis Jalur dan Aplikasi SPSS Versi 25". Buku ini berhubungan dengan cara-cara pengumpulan data, pengolahan atau penganalisaan dan penarikan kesimpulan berdasarkan kumpulan data serta penganalisaan secara manual dengan menggunakan Aplikasi SPSS Versi 25. Buku ini memberikan contoh-contoh aplikatif dalam tahapan mengerjakan dan penyelesaian permasalahan dengan Analisis Jalur.

Buku ini mengulas tentang konsep analisis jalur, populasi dan sampel, validasi dan reliabilitas instrument, statistik deskriptif, variabel penelitian, pengujian persyaratan analisis, uji koefisien antara variabel eksogen dengan variabel endogen, perhitungan koefisien jalur variabel, pengujian hipotesis, perhitungan pengaruh langsung dan tidak langsung. Disamping itu buku ini menjelaskan langkah-langkah dalam analisis jalur seperti melakukan uji normalitas setiap data, mengambarkan bentuk hubungan struktural antar variabel, menghitung koefisien jalur serta pengujian keberartian koefisien jalur dengan bantuan SPSS versi 25 .

Pada kesempatan ini, penulis mengucapkan terima kasih kepada Rektor Universitas Almuslim dan Civitas Akademika Universitas Islam Kebangsaan Indonesia yang tidak kenal lelah memberikan dukungan dan motivasi kepada penulis untuk terus mengaktualisasi diri menjadi dosen yang berkompetensi dan profesional dalam menulis buku sebagai bentuk pengembangan diri dan kompetensi keilmuan.

Semoga buku ini menjadi modul pembelajaran dan salah satu buku rujukan untuk mahasiswa dan dosen serta pembaca, terutama pembaca yang memiliki kesamaan model rancangan riset melalui pendekatan deskriptif dan inferensial. Buku ini juga dilengkapi 
dengan langkah tutorial SPSS Versi 25 untuk membantu menyesaikan pengolahan data. Besar harapan penulis untuk masukan konstruktif dari pembaca untuk cetakan revisi berikutnya.

Bireuen, Juli 2019

Penulis 


\section{DAFTAR ISI}

KATA PENGANTAR

DAFTAR ISI

DAFTAR GAMBAR

BAB 1. PENDAHULUAN

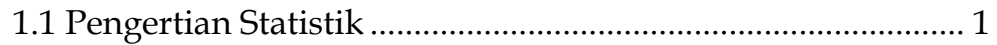

1.2 Klasifikasi Statistika ................................................................ 1

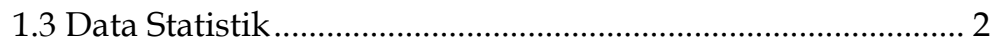

1.4 Macam-Macam Data ............................................................. 2

1.5 Skala Pengukuran pada Data .................................................. 4

\section{BAB 2. ANALISIS JALUR}

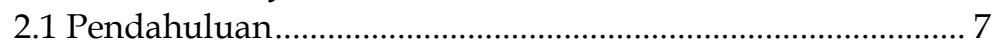

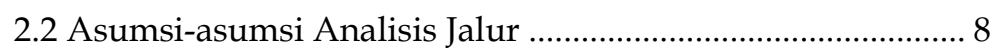

2.3 Manfaat Analisis Jalur ................................................................. 8

2.4 Beberapa Istilah dalam Analisis Jalur ..................................... 9

2.5 Model Analisis Jalur Sederhana .............................................. 10

2.6 Model Analisis Jalur .................................................................... 11

\section{BAB 3. POPULASI DAN SAMPEL}

3.1 Pendahuluan.......................................................................... 13

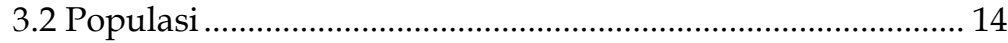

3.3 Sampel ....................................................................................... 15

3.4 Contoh Populasi dalam Penelitian ...................................... 18

3.5 Penarikan sampel ............................................................. 18

BAB 4. VALIDITAS, RELIABILITAS INSTRUMEN

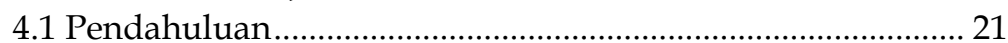

4.2 Uji Validitas ............................................................................ 22

4.3 Uji Reliabilitas..................................................................... 23

4.4 Validitas dan Reliabilitas Instrumen Budaya Organisasi $\left(\mathrm{X}_{1}\right) 25$

4.5 Validasi dan Reliabilitas Instrumen Budaya Organisasi ...... 35

\section{BAB 5. STATISTIK DESKRIPTIF}

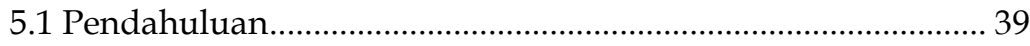

5.2 Perhitungan Distribusi Frekuensi............................................... 39

5.3 Pengukuran Tendensi Sentral .................................................... 41

5.4 Persentase Distribusi Skor Penelitian........................................... 44

5.5 Identifikasi Tingkat Kecenderungan Ubahan Penelitian ......... 45

5.6 Pengujian Statistik Deskriptif Bantuan SPSS Versi 25 .............. 46 
BAB 6. VARIABEL KONSEPTUAL DAN DEFENISI OPERASIONAL

6.1 Pendahuluan .52

6.2 Variabel Budaya Organisasi ....................................................... 53

6.3 Perilaku Kepemimpinan ............................................................ 54

6.4 Motivasi Berprestasi............................................................... 55

6.5 Variabel Kepuasan Kerja ........................................................ 55

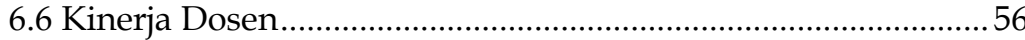

\section{BAB 7. PENGUJIAN PERSYARATAN ANALISIS}

7.1 Pendahuluan ................................................................................ 58

7.2 Perhitungan Normalitas Data dengan Teknik Lilliefors..........59

7.3 Uji Normalitas dengan Bantuan SPSS Versi 25 ........................ 62

7.4 Perhitungan Uji Kelinearan dan Keberartian pada Variabel

Kepuasan Kerja atas Budaya Organisasi .................................. 68

7.5 Uji Linearitas dengan Bantuan SPSS Versi 25

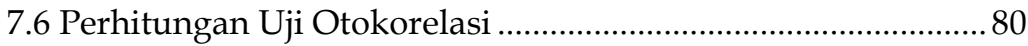

7.7 Uji Otokorelasi dengan Bantuan SPSS Versi 25 ......................81

7.8 Perhitungan Multikolinearitas ................................................. 86

7.9 Uji Multikolinearitas dengan Bantuan SPS Versi 25................. 90

\section{BAB 8. UJI KOEFISIEN ANTARA VARIABEL EKSOGEN DENGAN VARIABEL ENDOGEN}

8.1 Pendahuluan .96

8.2 Prosedur Uji Koefisien antara Variabel Eksogen dengan

Variabel Endogen

8.3 Uji Korelasi dengan Bantuan SPSS Veri 25

\section{BAB 9. PERHITUNGAN KOEFISIEN JALUR VARIABEL}

9.1 Pendahuluan

9.2 Perhitugan Koefisien Jalur Variabel Penelitian

\section{BAB 10. PERHITUNGAN UJI HIPOTESIS}

10.1 Pendahuluan

10.2 Persamaan Substruktur I

10.3 Persamaan Substruktur II

\section{BAB 11. PERHITUNGAN PENGARUH LANGSUNG DAN TIDAK LANGSUNG}

11.1 Pendahuluan 128

11.2 Prosedur Perhitungan Pengaruh Langsung dan Tidak 


\section{DAFTAR TABEL}

Tabel 3.1 Keadaan Populasi Dosen Tetap yang Memiliki Jabatan Akademik pada Perguruan Tinggi Swasta di Provinsi Aceh

Tabel 3.2 Keadaan Sampel Dosen Tetap yang Menjadi Sampel menurut Jabatan Akademik pada Perguruan

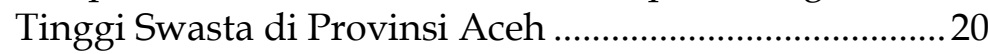

Tabel 3.3 Kisi-kisi Variabel Budaya Organisasi $\left(X_{1}\right) \ldots \ldots \ldots \ldots \ldots \ldots . . . . .36$

Tabel 3.8 Matriks Korelasi antar Variabel...................................... 97 


\section{DAFTAR GAMBAR}

Gambar 2.1 Model Analisis Jalur Sederhana ………………............. 11

Gambar 2.2 Model Regresi Berganda dan Model Mediasi................ 11

Gambar 2.3 Model Kombinasi.......................................................... 12

Gambar 5.1 Histogram Budaya Organisasi ......................................... 41

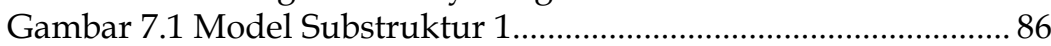

Gambar 7.2 Model Substruktur 2...................................................... 88

Gambar 8.1 Diagram Jalur ................................................................. 97

Gambar 9.1 Substruktur I. Hubungan kausal $\mathrm{X}_{1}, \mathrm{X}_{2}, \mathrm{X}_{3}$

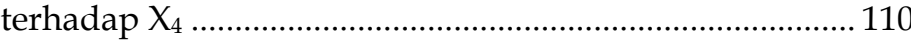

Gambar 9.2 Substruktur I. Hubungan kausal $X_{1}, X_{2}, X_{3}$

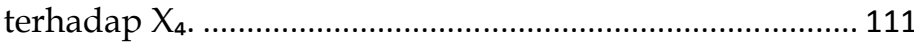

Gambar 9.3 Substruktur I. Hubugan kausal $X_{1}, X_{2}, X_{3}$ terhadap $X_{4}$ yang telah diperoleh koefisien jalur ................................ 114

Gambar 9.4 Substruktur II. Hubungan kausal $X_{1}, X_{2}, X_{3}$

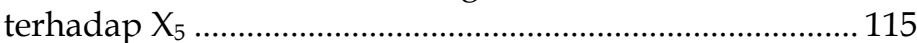

Gambar 9.5 Substruktur II. Hubungan kausal $X_{1}, X_{2}, X_{3}, X_{4}$ terhadap $\mathrm{X}_{5}$ yang telah diperoleh koefisien jalur 117 


\section{DAFTAR PUSTAKA}

Arikunto, S. (2002). Organisasi dan Administrasi Pendidikan Teknologi dan Kejuruan, edisi 1. Jakarta: Rajawali

Duncan, O.D. (1969). Some linear models of two-wave, two-variable panel analysis. Psychological Bulletin, 72: 177-182

Hasan, I. (2001). Analisis Data Penelitian dengan Statistik. Jakarta: Bumi Aksara

Kerlinger, (1986). Asas-asas Penelitian Behavioral. Yogyakarta: Gadjah Mada University Press. p. 796

Kopertis Wilayah XIII Aceh, (2014). Direktori Perguruan Tinggi Swasta Aceh. Banda Aceh: Kopertis Wilayah XIII Aceh

Kuncoro dan Riduwan, E.A. (2003). Cara Mudah Menggunakan dan Memakai Path Analysis (Analisis Jalur). Bandung: Alfabeta

Margono, S. (2012). Metodologi Penelitian Pendidikan. Jakarta: PT Rineka Cipta

Muhammad, (2013). Statistik untuk Penelitian Pendidikan. Yogyakarta: Parama Publishing. p. 101

Nidjo Sandjojo, (2010). Metode Analilis Jalur (Path Analysis) dan Aplikasinya. Jakarta: Sinar Harapan. p. 64

Pedhazur, J. Elazar. (1982). Multiple Regression in Behavioral Research Explanation and Prediction. USA: CBS College. p. 582

Pedhazur, J. Elazar. (1982). Multiple Regression in Behavioral Research Explanation and Prediction. USA: CBS College

Ridwan dan Engkos, (2010). Cara Menggunakan dan Memaknai Analisis Jalur. Bandung: CV. Alfabeta. p. 2

Rutherford, R. D. dan Choe, M.K. (1993). Statistical model for causal analysis 
Stephen P. Robbins, (1998). Organizational Behaviour. New Jersey: Prentice Hall International Inc. p. 135

Sudijono. Pengantar Statistik Pendidikan. Jakarta: Rajawali Pers, (2009). Hal. 170-176

Sudjana, (2005). Metoda Statistika. Bandung: Rajawali

Sugiyono, (2008). Statistika untuk Penelitian. Bandung: Alfabeta

Sugiyono, (2005). Statistika untuk Penelitian. Bandung: Alfabeta. p. 285

Sukmadinata, N.S. (2011). Pengembangan Kurikulum Teori dan Praktek. Bandung: Remaja Rosdakarya

Supardi. Aplikasi Statistik dalam Pendidikan. Jakarta: Prima Ufuk Semesta, (2013). p. 157

Webley, P. \& Lea, S. (1997). PSY6003 Advanced statistics: Multivariate analysis II: Manifest variables analyses. Modified February, 21

Wright, P.G. (1921). The tariff on animal and vegetable oils. New York: Macmillan. 


\section{RIWAYAT HIDUP}

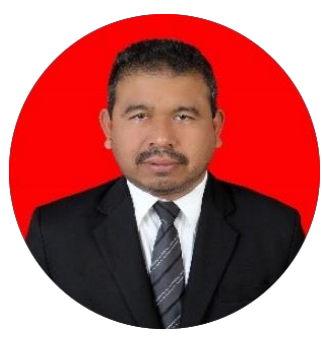

Dr. Marwan Hamid, M.Pd. Lahir di Teupin Mane, Bireuen, Aceh pada tanggal 10 Mei 1967. Penulis menyelesaikan pendidikan Sekolah Dasar Negeri Teupin tahun 1979, lulus Sekolah Menengah Pertama Negeri Juli tahun 1982, lulus Sekolah Menengah Atas Negeri 1 Bireuen tahun 1985, lulus Fakultas Keguruan dan Ilmu Pendidikan Prodi Pendidikan Akuntansi Universitas Syiah Kuala tahun 1991, dan lulus PPs Prodi Magister Manajemen Pendidikan Universitas Negeri Malang tahun 2004. Pada tahun 2009 melanjutkan studi Program Doktor (S3) di Program Pascasarjana Prodi Manajemen Pendidikan pada Universitas Negeri Medan.

Tahun 1993 merupakan hari kebahagiaan bagi penulis diterima sebagai PNS guru pada SMK Negeri 3 Lhokseumawe mengasuh mata pelajaran Komputer dan Pengantar Akuntansi, Akuntansi Intermediate, dan Akuntansi Lanjutan. Tahun 2006 pindah status PNS guru menjadi PNS dosen DPK Kopertis Wil-I Aceh-Sumut ditempatkan pada Universitas Almuslim Bireuen Aceh sampai sekarang. Penulis pernah menjabat sebagai Wakil Kepala Sekolah SMK 3 Lhokseumawe bidang Humas dan Kerjasama, Wakil ketua Bidang Akademik Sekolah Tinggi Tehnik Informatika dan Komputer Lhokseumawe, Wakil Rektor Bidang Administrasi Umum dan Keuangan Universitas Almuslim Bireuen, Kepala Badan Pemberdayaan Masyarakat Kabupaten Bireuen, Wakil Rektor Bidang Akademik Universitas Almuslim Bireuen, dan saat ini menjabat sebagai Rektor Universitas Islam Kebangsaan Bireuen. Saat ini penulis aktif dalam beberapa penelitian dan pengabdian. Penulis juga aktif menulis artikel publikasi jurnal ISSN dan terindeks Internasional. Pengalaman penulisan buku dengan judul Pengantar Komputer, Pendidikan Akhlak Santri Dayah, dan Pengembangan Kurikulum Kontruktivisme, sedangkan buku Analisis Jalur Dan Aplikasi SPSS Versi 25 merupakan buku ke empat. Untuk berdiskusi terkait buku ini penulis dapat dihubungi pada alamat berikut: Alamat kantor: Rektorat Universitas Islam Kebangsaan Indonesia, Blang Blahdeh, Kecamatan Jeumpa, Kabupaten Bireuen, Aceh. Alamat email: marwan.dayah@gmail.com. 


\section{RIWAYAT HIDUP}

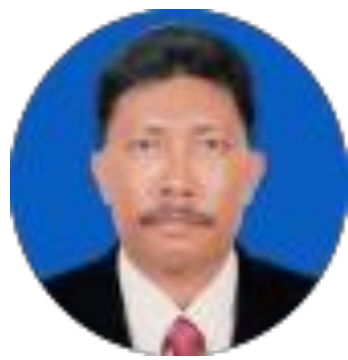

Dr. Ibrahim Sufi, M.Pd. Penulis merupakan anak bungsu dari tujuh bersaudara keluarga Imum Syiek Sufi dan Syammah Su'ud. Lahir tanggal 15 Mei 1967 di Gampong LangNibong Sampoyniet Kecamatan Baktya Barat Aceh Utara. Pendidikan dasar dan menengah pada SD Negeri dan SMP Negeri Sampoyniet 1974 sehingga tahun 1983. Diterima pada SMA Negeri Panton Labu Aceh Utara dari tahun 1983 sehingga tahun 1986. Peringkat sarjana muda education dari pada tahun 1987 sehingga 1992 program Biologi Fakultas Keguruan Universitas Serambi Mekkah Aceh Indonesia dan program Pascasarjana pada Universitas Negeri Malang dalam program Biologi Education tamat tahun 1999.

Program Doktoral pada College Art and Science (CAS) Universitas Utara Malaysia tamat pada 2016. Tugas sebagai pensyarah pada Universitas Serambi Mekkah Aceh dan aktif mengajar pada beberapa universiti swasta di Aceh. Pada masa kini mengasuh mata kuliah Kajian kurikulum, Genetika, Biologi Umum, Struktur Hewan, Dasar-dasar MIPA, dan beberapa mata kuliah asas umum lainnya. Aktif sebagai kommite sekolah SMP di Banda Aceh sebagai pengabdian dalam bidang pendidikan untuk menyokong pemerintah Aceh dalam mewujudkan program Aceh Caro'ong dan Aceh Hebat. dalam Provinsi Aceh.!!. 


\section{RIWAYAT HIDUP}

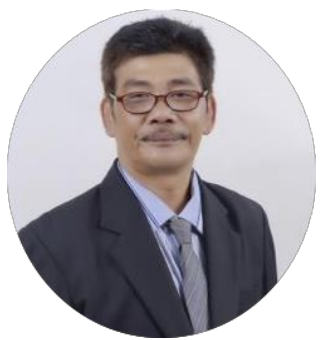

Drs. Wen Konadi, M.Si. Penulis lahir di Lhokseumawe, 6 November 1964, merupakan Lektor Bidang Statistik Demografi pada Universitas Almuslim Bireuen Aceh. Penulis memperoleh sarjana dbidang Statistika Ekonomi (1989, di Unisba Bandung), dan S2 bidang Kajian Kependudukan (2000, UIJakarta). Pengalaman Kerja sebagai staf pengajar FE Universitas Almuslim, 2008 sampai saat ini. Pernah menjabat sebagai ketua STIE Kebangsaan Bireuen-Aceh, 2014-2019 dan sampai saat ini sebagai Wakil Rektor I Bid. Akademik UNIKI - Aceh.

Saat penulis sudah menerbitkan beberapa karya tulis, telah diseminasikan, antara lain: Keterkaitan antara Demokrasi Politik, demokrasi Ekonomi dan sistem Ekonomi Kerakyaratan" Jurnal Mimbar LPPM UNISBA, Volume XXI, No.03, Juli-Sept 2005 (ISSN: 0215-8175) Terakreditasi DIKTI; Analysis Of Factors Consumer Preferences Ojek Online In Indonesia Using Conjoint Technique Analysis, Almuslim International Conference on Science, Technology, and Society-1, (2015); Empat Jalur Peningkatan SDM Pekerja suatu Kajian Teoritis, Jurnal Indonesia Membangun STIE INABA, Vol.4 No.3 Nop-Feb 2006 (ISSN : 1412-6907); Estimasi angka Migrasi Keluar Perdesaan, Majalah Ilmiah Unimus "VARIASI" Vol.1 No.1 Juni 2009 (ISSN: 2085-6172); Perhitungan dan Analisis Kontribusi dan Benefit Dana Pensiun dengan Metode Spread Devisit, Majalah Ilmiah Unimus "VARIASI" Vol 2 No 4, Juni 2010 (ISSN: 2085-6172); Model Peningkatan Kualitas SDM Penduduk Usia Kerja yang Unggul Profesional dan Islami, Jurnal Ekonomika Univ. Almuslim Vol. I No.1, Maret 2010, (ISSN: 2086-6011); Pengaruh Pengembangan SDM Melalui Diklat Terhadap Produktivitas Kerja Pada Pegawai Kecamatan Samalanga Kabapaten Bireuen, Jurnal Kebangsaan, Vol.6 No.11 (Januari 2017). 


\section{RIWAYAT HIDUP}

Drh. Yusrizal Akmal. M.Si. Penulis

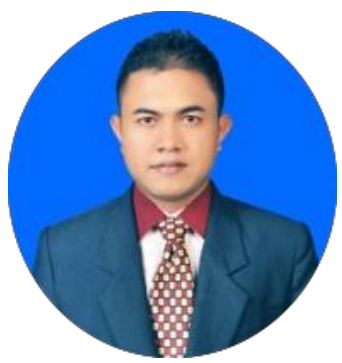
dilahirkan di Gampong Raya Dagang pada tanggal 22 Januari 1987, dari Ayahanda Usman Ismail dan Ibunda Yusriati (Alm). Tahun 2003 penulis melanjutkan studi ke Sekolah Menengah Atas Negeri 01 Bireuen dan tamat tahun 2005. Ditahun yang sama, penulis diterima di Fakultas Kedokteran Hewan Universitas Syiah Kuala (UNSYIAH) Banda Aceh. Penulis mendapatkan gelar sarjana Kedokteran Hewan (S.KH) pada tahun 2009, melanjutkan Program Profesi Dokter Hewan (PPDH) dan tamat pada tahun 2011 serta mendapat gelar Dokter Hewan (Drh). Kemudian pada tahun 2012 penulis mendapatkan kesempatan melanjutkan dengan menerima bantuan beasiswa selama dua tahun dari BU DIKTI pascasarjana S2 di Prodi Anatomi dan Perkembangan Hewan, Departemen Anatomi Fisiologi dan Farmakologi Institut Pertanian Bogor (IPB) dan tamat pada tahun 2014 serta mendapat gelar Magister Sain (M.Si). Saat ini penulis berkerja sebagai dosen aktif sejak tahun 2015 di prodi Budidaya Perikanan, Fakultas Pertanian Universitas Almuslim Bireuen, dan sebagai Ka.UPT Laboratorium MIPA Universitas Almuslim Bireuen.

Buku ini merupakan buku ketiga Penulis, setelah sebelumnya Penulis menerbitkan buku ajar ber-ISBN berjudul Anatomi dan Fisiologi Manusia (2018), serta Buku dengan judul Osteologi Ikan Kureling (2019). Penulis juga aktif dalam menulis jurnal terakreditasi Nasional dan jurnal terindeks scopus. Saat ini penulis sudah memperoleh dua sertifikat paten (IN Patent EC00,201,809,232) dan (IN Patent EC00,201,823,387). Untuk berdiskusi terkait buku ini penulis dapat dihubungi pada alamat berikut: Alamat kantor: Program Studi Budidaya Perikanan, Fakultas Pertanian, Universitas Almuslim Bireuen, Jalan Almuslim Kec. Peusangan, Kode pos 24267, Telepon (0644) 442166. Alamat rumah: Jalan Pante Lheung 2, Desa Blang Panjoe, Kec. Peusangan, Kab. Bireuen, Aceh. Kode pos 24267. Alamat email: drh.yusrizal.akmal.msi@gmail.com. 